\title{
ANALISIS EFISIENSI PENYALURAN AIR IRIGASI KAWASAN KEMUMU KABUPATEN BENGKULU UTARA (Tinjauan saluran sekunder)
}

\author{
Aditta Setio Rahayu $^{(1)}$, Khairul Amri ${ }^{(2)}$ Besperi $^{(3)}$ \\ ${ }^{1)}$ Alumni Program Studi Teknik Sipil Fakultas Teknik UNIB \\ Jl. W.R. Supratman, Kandang Limun,Bengkulu 38371, \\ e-mail : sipil@unib.ac.id \\ ${ }^{2), 3)}$ Staf Pengajar Program Studi Teknik Sipil UNIB, Bengkulu
}

\begin{abstract}
Abstrak
Efisiensi irigasi merupakan faktor penentu utama dari sistem kerja jaringan irigasi. Efisiensi irigasi di dasarkan asumsi sebagian dari jumlah air yang diambil akan hilang baik di saluran maupun di petak sawah. Kehilangan air yang diperhitungkan untuk efisiensi meliputi kehilangan air ditingkat tersier dan sekunder, besarnya kehilangan air tersebut dipengaruhi oleh panjang saluran, luas permukaan saluran, keliing basah saluran dan kedudukan air tanah. Analisis yang dilakukan pada penelitian ini adalah menghitung besaran nilai efisiensi pada saluran sekunder dan tersier kawasan irigasi kemumu kabupaten Bengkulu Utara. Efisiensi yang di perhitungkan berdasarkan panjang saluran, luas penampang basah saluran, kecepatan air, kehilangan air, evaporasi dan rembesan pada saluran. Nilai kehilangan air rata-rata pada saluran sekunder adalah $26,12 \mathrm{~m}^{3} / \mathrm{dtk}$. Rembesan rata-rata pada saluran sekunder adalah $5,06 \times 10^{-4} \mathrm{~mm} / \mathrm{hari}$. Nilai evaporasi satu tahun adalah $0,05 \mathrm{~mm} / \mathrm{hari}$. Hasil dari penelitian ini menyatakan bahwa efisiensi pada saluran sekunder dapat dikatakan dalam keadaan tidak efisien untuk menyalurkan air dari saluran primer ke saluran tersier dengan nilai efiensi sebesar 11,92Diharapkan dari hasil analisis ini saluran yang tidak efisien dapat ditingkatkan efisiensinya guna terpenuhinya kebutuhan air pada persawahan di kawasan Kemumu Bengkulu Utara, diadakan peningkatan dengan membuat irigasi dari beton dan melakukan perawatan secara rutin.
\end{abstract}

Kata kunci : Efisiensi, Kehilangan Air, Evaporasi, Rembesan

\begin{abstract}
Irrigation efficiency is a major determinant in the system of scheme irrigation. Irrigation efficiency is assumed as part of water would be lost either in the channel or at the rice terraces. Water loss estimate in efficiency include loss of water efficiency tertiary and secondary level, water loss is influenced by the length of the channel, the surface area of the channel, the wet cross section and the position of groundwater. The analysis in this study is to calculate the value of the efficiency the secondary and the tertiary canals of irrigation of Kemumu, North Bengkulu. Efficiency is accounted based on the length of the channel, sectional area of wet channel, water velocity, water loss, evaporation and seepage channel. The water loss average of secondary channel is $26,12 \mathrm{~m}^{3} / \mathrm{sec}$. seepage average for secondary channel is $5,06 \times 10^{-4}$ $\mathrm{mm} /$ day. Evaporation in one year is $0,05 \mathrm{~mm} /$ day. The results of this study stated that the efficiency of the secondary channel efficiently deliver water from the primary channel to channel tertiary the average of efficiency is about 11,92\%. The result of this analysis is expected that not efficient channels in Kemumu North Bengkulu can be fixed, so thewater that rice field needed can be fulfilled. The channels can be fixed with some ways, such as making the concrete irrigation and doing the rutine maintenance.
\end{abstract}

Keywords: Efficiency, Water Loss, Evaporation, Seepage 


\section{PENDAHULUAN}

Efisiensi irigasi merupakan faktor penentu utama dari sistem kerja jaringan irigasi. Efisiensi irigasi terdiri dari efisiensi pengaliran yang terjadi di jaringan utama atau jaringan primer.

Terjadi beberapa permasalahan dalam pengaliran air yang disebabkan oleh evaporasi dan rembesan yang dipengaruhi oleh keadaan aliran. Diperkirakan panjang saluran Tersier dan sekunder pada irigasi kemumu adalah $5.663 \mathrm{~m}$.

Efisiensi dari penyaluran air pada saluran sekunder dan tersier yang berada di Kemumu dinilai kurang mampu memenuhi kebutuhan air pada lahan pertanian. Terlihat dari saluran yang telah mengalami kerusakan baik retak rambut maupun pecah, terdapat beberapa saluran yang masih menggunakan tanah asli. Keadaan dilapangan inilah yang menyebabkan penyaluran air irigasi menjadi tidak efisien.

Tujuan dari penelitian ini adalah menghitung nilai efisien penyaluran air, evaporasi, kehilangan air dan rembesan di saluran sekunder dan saluran tersier, pada daerah irigasi Kemumu kecamatan Arma Jaya Kabupaten Bengkulu Utara.

Penelitian ini mengharapkan saluran yang tidak efisien dapat ditingkatkan efisiensinya guna terpenuhinya kebutuhan air pada persawahan di kawasan Kemumu Bengkulu Utara, diadakan peningkatan dengan membuat irigasi dari beton dan melakukan perawatan secara rutin.

\section{METODOLOGI PENELITAN}

Penelitian ini dilakukan selama 5 hari di daerah irigasi kemumu kabupaten Bengkulu utara provinsi Bengkulu dan pengolahan data dilakukan selama 7 hari.

Alat dan bahan yang digunakan pada penelitian ini adalah alat tulis, roll meter, current meter, kamera, laptop dan kalkulator.

Untuk mengukur kehilangan air, dilakukan metode pengukuran debit inflow (pangkal saluran) dan debit outflow (ujung saluran) menggunakan current meter.

\section{HASIL DAN PEMBAHASAN}

Secara administrasi jaringan irigasi Kemumu terletak di desa Kemumu Kecamatan Arma Jaya Kabupaten Bengkulu Utara Provinsi Bengkulu dan secara geografis terletak pada posisi 03 11" 07' LS 101 59" 54' BT. Luas irigasi Kemumu yaitu 785 Hektar. Sumber air irigasi adalah sungai Air Nokan.. Keadaan iklim Kabupaten Bengkulu Utara memiliki iklim tropis yaitu musim hujan dan musim kemarau. Pengamatan stasiun Klimatologi Pulau Baai menunjukkan rata-rata kelembaban udara $83 \%$ per bulan. Curah hujan berkisar 184 $\mathrm{mm} /$ bulan. Tingkat penguapan $9,97 \mathrm{~mm} /$ hari temperatur udara per bulan minimum 21,7 $\mathrm{C}$ dan maksimum 35,3 C dan rata-rata kecepatan angin berkisar 1,04 m/dtk.

Lokasi Penelitian dapat dilihat pada gambar skema jaringan berikut :

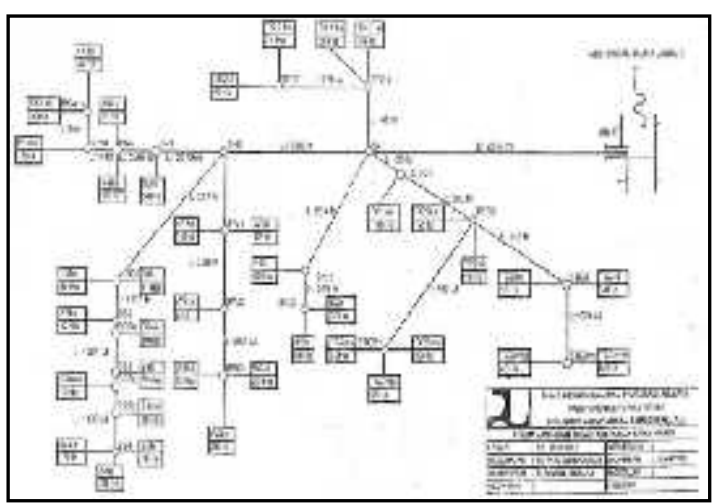

Gambar 1. Skema Jaringan

\section{EFISIENSI SALURAN SEKUNDER}

Untuk menghitung efisiensi penyaluran dilakukan pengukuran kecepatan aliran air pada saluran sekunder, data kecepatan aliran dapat dilihat pada grafik berikut : 


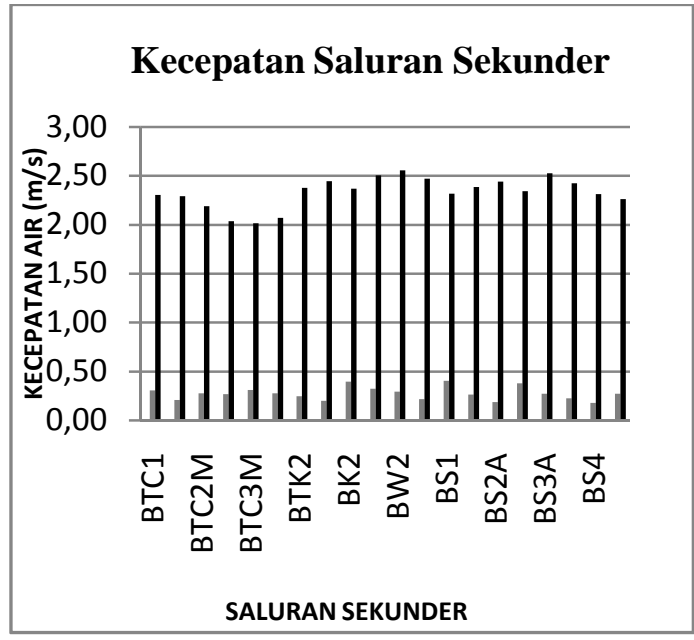

Gambar 2. Kecepatan Saluran Skunder

Kecepatan aliran air dihitung menggunakan current meter pada ujung dan pangkal saluran sekunder, setelah didapatkan nilai kecepatan aliran air maka akan didapatkan nilai debit aliran tersebut.

Kecepatan rata-rata pada pangkal saluran ialah $2,331 \mathrm{~m}^{3} / \mathrm{dtk}$ dan pada ujung saluran ialah $0,404 \mathrm{~m}^{3} / \mathrm{dtk}$.

Debit aliran saluran sekunder dapat dilihat pada grafik berikut :

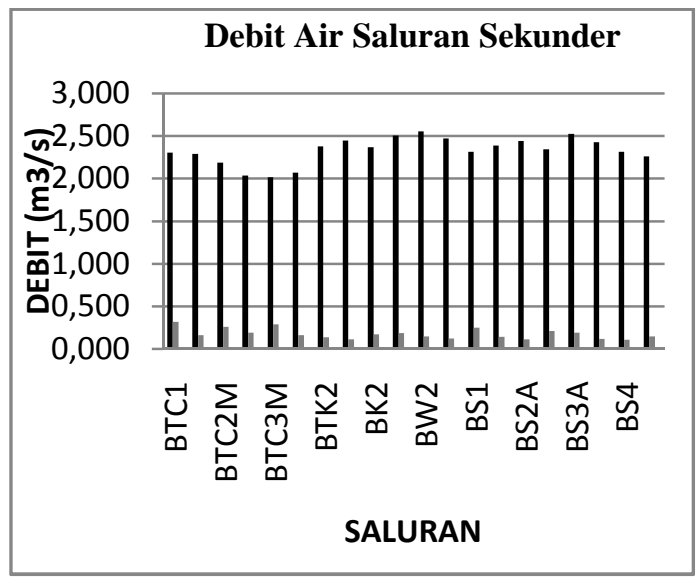

Gambar 3. Debit Air Saluran Skunder

Debit aliran air didapatkan berdasarkan rumus:

$$
\mathrm{Q}=\mathrm{A} \times \mathrm{V}
$$

Dimana: A : keliling basah saluran

$\mathrm{V}$ : kecepatan aliran air pada saluran.
Debit air rata-rata pada pangkal saluran ialah $1,48 \mathrm{~m}^{3} / \mathrm{dtk}$ dan pada ujung saluran ialah $0.18 \mathrm{~m}^{3} / \mathrm{dtk}$.

Setelah diketahui nilai debit dari setiap saluran maka dapat diketahui berapa besaran kehilangan air yang terjadi pada saluran, kehilangan air dapat diketahui dengan rumus :

Kehilangan air $=Q_{\text {ujung }}-Q_{\text {pangkal, }}$ (2)

Dimana: $\mathrm{Q}_{\text {ujung }}$ : Debit yang terdapat pada ujung saluran

$\mathrm{Q}_{\text {pangkal,: }}$ Debit yang terdapat pada pangkal saluran

Kehilangan air rata-rata yang terjadi pada saluran sekunder adalah $1,31 \mathrm{~m}^{3} / \mathrm{dtk}$.

Efisiensi saluran sekunder dapat dilihat pada grafik berikut :

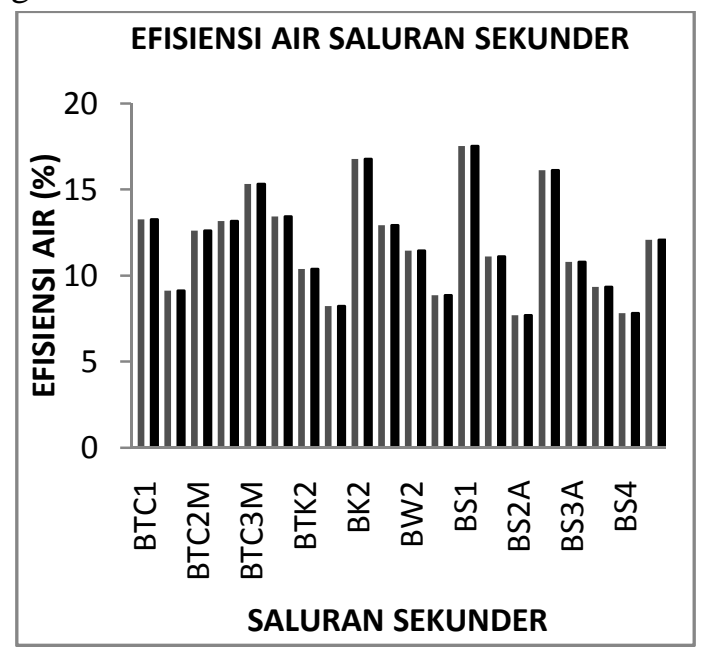

Gambar 4. Efisiensi Air Saluran Skunder

Nilai efisiensi penyaluran aliran air dapat dihitung dengan rumus :

$$
\text { Efisiensi }=\frac{Q_{\text {Ujung }}}{Q_{\text {Pangkal }}} \times 100 \%
$$

Dimana : $\mathrm{Q}_{\text {ujung }}$ : Debit yang terdapat pada ujung saluran

$\mathrm{Q}_{\text {pangkal,: }}$ : Debit yang terdapat pada pangkal saluran

Nilai efisiensi rata-rata pada saluran sekunder adalah $11,92 \%$, saluran ini dinilai tidak efisien untuk menyalurkan air ke saluran tersier dikarenakan syarat yang 
diberikan besrdasarka perencanaan irigasi KP-01 tahun 1996 efisiensi untuk saluran sekunder adalah 90\%. Tidak efisien nya penyaluran air ini disebabkan oleh beberapa aspek yaitu kerusakan yang terdapat pada saluran, evaporasi dan rembesan.

\section{EVAPORASI}

Evaporasi yang terjadi pada kawasan Irigasi Air Nokan Kemumu Kabupaten Bengkulu Utara ini sebesar $0,05 \mathrm{~mm} /$ hari selama 1 tahun.

Evaporasi dapat dihitung dengan rumus:

$$
\mathrm{E}_{0}=0,35 \mathrm{x}(\text { es }- \text { ed }) \times(0,5+0,54 \mathrm{x}
$$$$
\text { u2) }
$$

Dimana :

$$
\begin{aligned}
& \text { es : tekanan uap jenuh } \\
& \text { ed : tekanan uap sebenarnya } \\
& \text { u2 : kecepatan angin }
\end{aligned}
$$

Nilai evaporasi dapat dilihat pada grafik berikut :

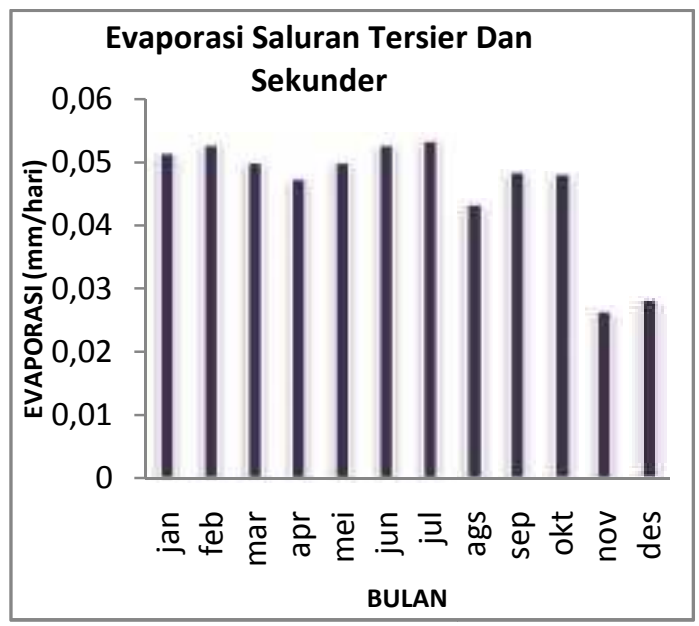

Gambar 5. Evaporasi Saluran

\section{REMBESAN}

Rembesan saluran sekunder dapat dilihat pada grafik berikut:

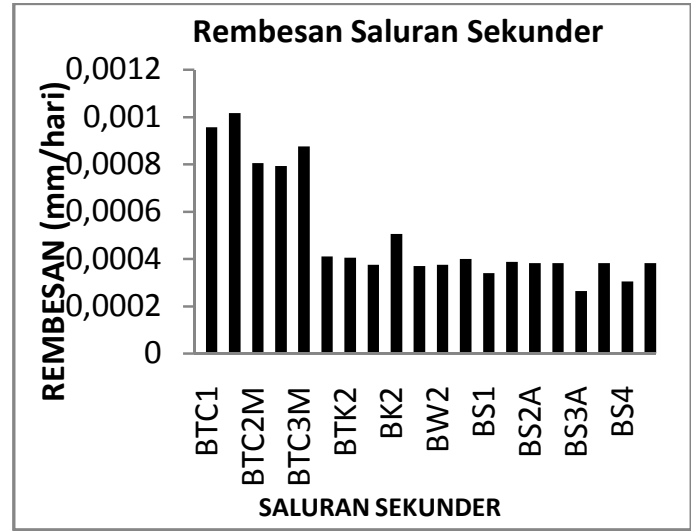

Gambar 5. Rembesan Saluran Skunder

Rembesan rata-rata pada saluran sekunder yang terjadi adalah $5,06 \times 10^{-4} \mathrm{~mm} / \mathrm{hari}$. Renbesan ini disebabkan oleh saluran yang retak maupun saluran yang pecah.

Rembesan saluran tersier dapat dilihat pada grafik berikut:

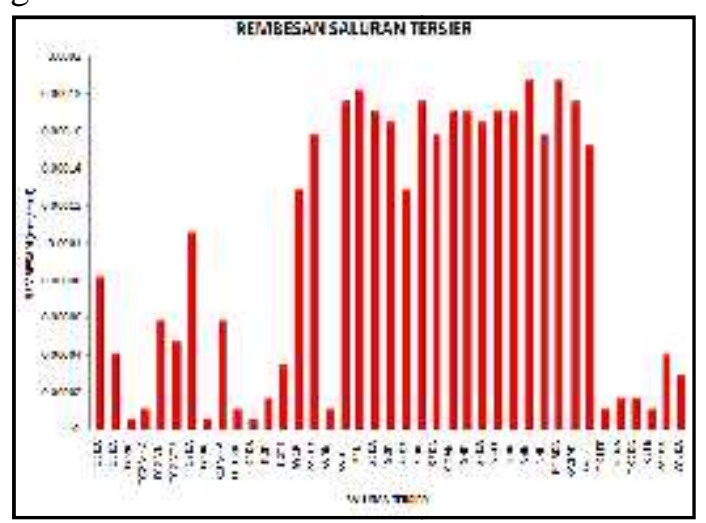

Gambar 6. Rembesan Saluran Tersier

Rembesan rata-rata pada saluran tersier yang terjadi adalah $9,70 \times 10^{-5} \mathrm{~mm} /$ hari. Renbesan ini disebabkan oleh saluran yang retak maupun saluran yang pecah.

\section{KESIMPULAN DAN SARAN}

\section{Kesimpulan}

Berdasarkan hasil penelitian melalui analisis data yang dilakukan maka dapat diambil kesi,pulan sebagai berikut:

a. Nilai efisiensi rata-rata saluran sekunder pada daerah irigasi Kemumu Bengkulu Utara adalah $11,92 \%$, artinya saluran sekunder ini dinilai tidak efisien untuk menyalurkan air ke saluran tersier. Standar efisiensi penyaluran air untuk 
saluran sekunder berdaasarkan perencanaan irigasi KP-01 ialah 90\%.

b. Nilai kehilangan air rata-rata pada saluran sekunder sebesar $0,16 \mathrm{~m}^{3} /$ det.

c. Nilai rembesan rata-rata saluran sekunder adalah $5,06 \times 10^{-4}$, rembesan terjadi akibat dari retakan yang terdapat pada saluran sekunder.

d. Evaporasi merupakan air yang hilang melalui proses penguapan pada daerah irigasi Kemumu penguapan rata-rata dalam 1 tahun adalah $0,05 \mathrm{~mm} /$ hari.

\section{Saran}

1. Sebaiknya Pemerintah melakukan pemeriksaan rutin pada saluran tersier dan sekunder dari sampah yang menyumbat saluran.

2. Sebaiknya pemerintah memperbaiki saluran yang rusak seperti retak dan pecah. Pada saluran yang masih merupakan tanah asli sebaiknya di lakukan pekerjaan pembuatan irigasi dari beton.

3. Pemerintah sebaiknya memberikan arahan pada petani agar terciptanya kerjasama antara pemerintah dan petani untuk memelihara saluran sekunder dan tersier yang ada pada Irigasi Kemumu Bengkulu Utara.

4. Untuk penyempurnaan hasil penelitian serta untuk mengembangkan penelitian lebih lanjut disarankan melakukan penelitian selanjutnya dengan pengukuran kcepatan aliran air yang menggunakan penentuan jarak pengukuran.

\section{DAFTAR PUSTAKA}

Ansori, A. dkk, 2013. Kajian Efektivitas Dan Efisiensi Jaringan Irigasi Terhadap Kebutuhan Air Pada Tanaman Padi (Studi Kasus Irigasi Kaiti samo Kecamatan Rambah
Kabupaten Rokan Hulu). Jurnal Teknik Sipil Universitas Pasir Pengairan, Rokan Hulu.

Asdak, C., 2007. Hidrologi Dan Pengelolaan Daerah Aliran Sungai. Gadjah Mada University Press, Yogyakarta.

Bacin, A.A. dkk, 2015. Efisiensi Penyaluran Irigasi BKA Kn 16 Lam Raya Daerah Irigasi Krueng Aceh. Jurnal Teknik Pertanian Universitas Syiah Kuala, Aceh.

Biahimo, Y. dkk, 2014. Analisa Efisieni Penyaluran Air Irigasi Dengan Sistem Informasi Geografis Bendung Lomaya Kabupaten Bone Bolango Provinsi Gorontalo. Jurnal Teknik Pertanian Fakultas Sam Ratulangi, Manado.

Direktorat Jendral Pengairan, 1986. Standar Perencanaan Irigasi. Departemen Pekerjaan Umum, Jakarta.

Dumairy, 1992. Ekonomika Sumber Daya Air. BPFE, Yogyakarta.

E.Hansen, Vaughn, dkk, 1992. Dasar-Dasar dan Praktek Irigasi, Erlangga, Jakarta.

Julya, S. 2013. Efisiensi Penyaluran Air irigasi Bendung Air Seluma Kabupaten Seluma. Skripsi Teknik Sipil Universitas Bengkulu. Bengkulu.

Kartasapoetra, A.G. dkk., 1994. Teknologi Pengairan Pertanian (irigasi), Bumi Aksara, Jakarta.

Lubis, J., Soewarno, dan Suprihadi, B., 1993. Hidrologi Sungai. Departemen Pekerjaan Umum, Jakarta.

Saputra, F dan Khairul, M., 2012. Analisa Efisiensi Penyaluran Air Irigasi Di Daerah Irigasi Lempake Kota Samarinda. Jurnal Teknik Sipil. Vol. 1. No.1. 
Sri Harto,B., 1993. Analisa Hidrologi. Gramedia, Jakarta.

Sudjawardi, 1987. Teknik Sumber Daya Air. Diklat Kuliah Jurusan Teknik Sipil UGM, Yogyakarta.

Tarigan, M.P dan Ramadhan, F. 2013. Evaluasi Kinerja Saluran Jaringan Jeuram Kabupaten Nagan Raya. Jurnal Teknik Sipil Universitas Sumatera Utara. Medan. 